\title{
The Role of Knowledge about Material Science and Engineering in Cultivating Students Majoring in Environmental Engineering
}

\author{
Haifeng Wen \\ School of Environment and Architecture \\ University of Shanghai for Science and Technology \\ Shanghai 200093, China
}

\author{
Kaihua Yan, Depeng Yang, Xin Shu, Junhao Zhuo, \\ Dengguang $\mathrm{Yu}$ * \\ School of Materials Science \& Engineering \\ University of Shanghai for Science and Technology \\ Shanghai 200093, China \\ E-mail address: ydg017@usst.edu.cn
}

\begin{abstract}
Environmental professional education is the most important segment in China's environmental work. For the undergraduate students majoring in the Environmental Engineering Specialty (EES), strengthening their capabilities through a suitable curriculum arrangement is necessary. Environmental Engineering and Material Science and Engineering, similar representatives of modern science and technology, have a large overlapped area. Interdisciplinary teaching for the undergraduate students majoring in them is easy and facile to be carried out. In this paper, we report how to foster the undergraduate students majoring in EES using knowledge about material science and engineering, particularly the advanced technology and advanced functional materials such as electrospinning and electrospun nanofibers. Electrospun zein nanofibers are useful materials for removing $\mathrm{Pb}$ ion from wastewater, and molecular sieve-loaded polyacrylonitrile nanofibers are highly efficacious in cleaning the volatile organic compound acetone from the atmosphere. These examples about material design, processing and applications can be vivid interdisciplinary teaching materials for promoting the students into professional talents in the fields of environmental engineering.
\end{abstract}

Keywords-environmental engineering; material Science and engineering; undergraduate students; interdisciplinary teaching

\section{INTRODUCTION}

In the university, all the undergraduate students have their own specialty. In China, the routine procedure about their curricula is two years' basic courses such as English, Mathematics, Physics, Chemistry followed by two years' professional courses. The professional courses, in many universities about natural science related majors, are divided into several sections, such as professional basic courses, professional core courses, professional development course, professional innovation course, selective courses, and graduation design. In the development courses, innovation courses and selective courses, the introduction about the professional knowledge of other related disciplines are very useful for broadening the students' ken and fostering their capability of innovation and practice. In this paper, the role of knowledge about material science and engineering in cultivating students majoring environmental engineering is suggested.

\section{OVERVIEW OF "ENVIRONMENTAL ENGINEERING SPECIALTY”}

The Environmental engineering specialty trains high-level applied talents with basic knowledge of water, gas, sound, solid waste pollution prevention and control, environmental planning, resource protection, and environmental impact assessment. Professional talents can be engaged in planning, design, management and research and development in environmental protection departments, industrial and mining enterprises, scientific research units, and thermal power plants. It is a new discipline. Its history of establishment and development is not very long. The Chinese government attaches great importance to environmental education and has established the guiding ideology of "environmental protection, education-based". Environmental education is a basic project of lifelong education, and a basic means to improve the national environmental moral quality and environmental scientific and cultural quality. Environmental professional education is the most important segment in China's environmental work.

For the college students graduated from Environmental Engineering, they should acquire the following knowledge and abilities: 1) mastering the fundamental theoretical knowledge about the typical four chemical subjects (i.e. inorganic chemistry, organic chemistry, analytical chemistry and physical chemistry), engineering drawing, engineering mechanics, microbiology, hydraulics, environmental monitoring, and other environmental engineering subjects; 2) mastering the basic principles and design methods about both water and air pollution control engineering, noise pollution control engineering, solid waste treatment, and resource engineering; 3) having the preliminary capabilities of pollutant monitoring and analysis, environmental monitoring, environmental quality assessment, environmental planning, and environmental management; 4) following the theoretical frontiers and developments of environmental science and technology; 5) grasping the basic methods of literature 
retrieval and data query, and have preliminary scientific research and practical working ability.

To achieve these capabilities, their curriculum should conclude the following lessons such as water pollution control engineering, air pollution control engineering, engineering drawing, environmental planning and management, environmental biochemistry, environmental soil science, environmental microbiology, solid waste treatment and disposal, environmental impact assessment, higher mathematics, linear algebra, probability theory, university physics, inorganic chemistry, analytical chemistry, organic chemistry, physical chemistry, university accounting computer foundation, physical pollution control, professional English. These lectures can be categorized into several sections: about chemistry, about engineering, about environmental applications, and the related fundamental knowledge about physical and mathematical methods.

\section{OVERVIEW OF "MATERIAL SCIENCE AND ENGINEERING SPECIALTY”}

Nowadays, material science is one of the three pillars of national economic development. Material Science and Engineering (MSE) is a relatively wide-caliber specialty involving materials science, materials engineering, chemistry, and a wide variety of applied sciences. This major is based on materials science, and the fundamental knowledge about chemistry and physics. It mainly studies the composition, structure, processing technology, properties and applications of materials. In fact, the history of human civilization is a history of how to make better use of materials and create materials. The continuous innovation and development of materials also greatly promote the development of social economy.

The lectures arranged for the students majoring in MSE when they are freshmen and sophomores are similar with those majoring in Environmental Engineering. The general basic subjects include advanced mathematics, linear algebra, general physics, computer foundation, C language, English and so on. Professional courses include inorganic chemistry, organic chemistry, physical chemistry, analytical chemistry, introduction to materials science and engineering, physical properties of materials, mechanics of materials, foundation of materials engineering, basic experiments of materials specialty, mechanical properties of Engineering materials, modern materials research technology, and advanced methods for material characterization.

\section{INTERDISCIPLINARY TEACHING BETWEEN TWO SUBJECTS}

Apparently, the subject of Environmental Engineering and the subject of Material Science and Engineering have no direct relationship. But from the above-mentioned introductions of these two subjects, they have many common lessons for the students. They both need the college students to understand the mathematics for building models in applications, need them to understand physical methods for analyses and characterization, and need them to have relative comprehensive chemistry knowledge for practices and innovations.
These two disciplines have a large overlapped area, as diagrammed in Fig. 1. They are similarly representatives of modern science and technology. Interdisciplinary teaching for the undergraduate students majoring them is facile to be carried out. Particularly, when some concrete and common advanced technologies, applications or functional materials are involved, the lessons can be almost the same. For example, the electrospun nanofibers for cleaning our environments are excellent teaching materials for college students majoring in Environmental Engineering, which are hot and popular topics in the fields of material science and engineering, nanoscience and electrohydrodynamic atomization. Finally, complete content and organizational editing before formatting. Please take note of the following items when proofreading spelling and grammar:

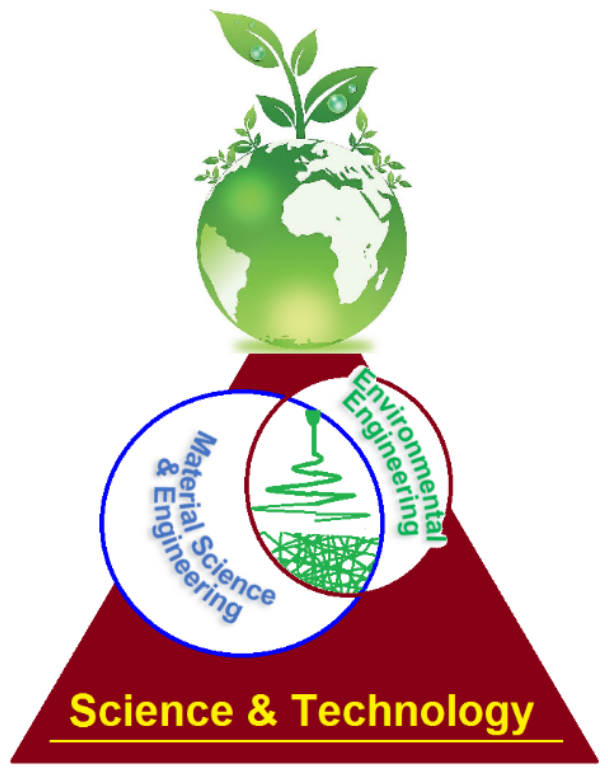

Fig. 1. A diagram showing that electrospinning/nanofibers can be a linkage between Environmental Engineering and Material Science and Engineering for cultivating undergraduate students.

\section{THE ROLE OF MSE KNOWLEDGE FOR CUltivating EE UNDERGRADUATE STUDENTS - WATER POLLUTION TREATMENT}

Fig. 2 shows a diagram about that the knowledge from material science and engineering can be fine teaching materials for cultivating the undergraduate students about how to treat pollution water. In this story, the raw material is zein, which is a water insoluble plant protein extracted from maize [1].

Although electrospinning is easy to implement for creating polymeric nanofibers [2-5]. The direct treatment of zein into nanofibers is difficult because of the frequent clogging of the spinneret. As a protein, zein is easy to interact with the spinneret, which is often composed of stainless steel. The easy evaporation of solvent would make zein easily forming semisolid substance and clinging on the nozzle of spinneret. As the volume of semi-solid substance increase, the spinneret is apt to be clogged and the working process is stopped. Thus, a modified coaxial electrospinning can be explored [6-12], in which pure solvent can be utilized as the sheath fluid to 
lubricate the spinning of core solution [13-15]. Thus, the knowledge about the raw material zein (from crops) can broaden the college students' ken about their environmental engineering's extension. And the knowledge about the advanced nanotechnology, i.e. the modified coaxial electrospinning for producing advanced nanomaterials, can be effectively utilized to give the students about new development directions of environmental engineering, to follow the most popular modern nano techniques, and to deepen the college students’ professional knowledge inclusion.

Certainly, the treatment of $\mathrm{Pb}$ polluted water should be contents that are totally included in the knowledge range that the undergraduate students should grasp well during the professional studies. Thus, starting from the raw materials, through the advanced material treatment processes, reaching the environmental applications can be a whole procedure for strengthening the interdisciplinary teaching on the undergraduate students majoring in environmental engineering.

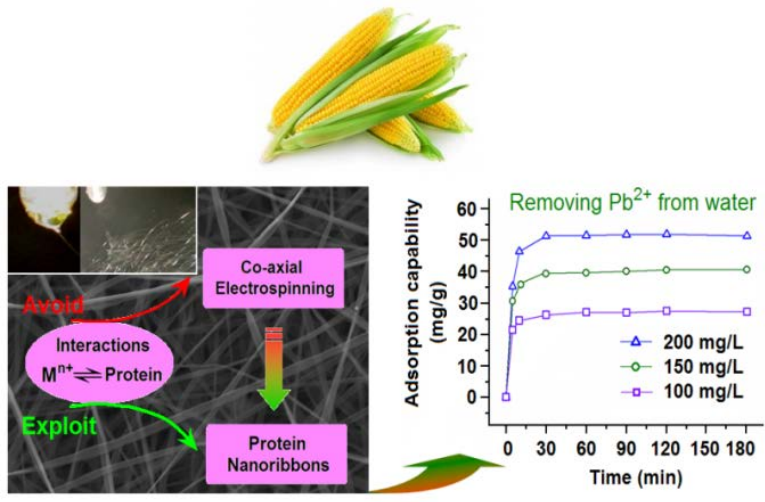

Fig. 2. A diagram showing that the knowledge about material science and engineering can be fine teaching materials for cultivating the undergraduate students about how to treat pollution water [1].

\section{THE Role OF MATERIAL SCIENCE AND ENGINEERING KNOWLEDGE FOR CULTIVATING ENVIRONMENTAL ENGINEERING UNDERGRADUATE STUDENTS - TREATMENT OF GAS POLLUTION}

Fig. 3 shows a diagram about that the knowledge from chemistry and material engineering can be nice teaching materials for cultivating the undergraduate students about how to clean volatile organic compounds (VOCs), a typical air pollution source [16].

In this teaching material, the topic is about a new approach, which can be exploited to prepare electrospun ordered porous honeycomb fibers. These fibers had the potential applications for maximal adsorption of VOCs. The starting working fluids were prepared by blending the self-assembled ordered porous material (OPM) and the filament-forming polymeric matrix polyacrylonitrile (PAN) into a solvent to form a co-dissolved solution, which could be treated into fibers using the typical single-fluid electrospinning process. OPM was distributed all over the PAN fibers, and PAN fibers with different contents of OPM were evaluated in terms of their adsorption performances on the model VOC - acetone. The experimental results showed that the honeycomb fibers' adsorption capability was elevated as the increase of OPM loaded in the PAN fibers. Based on the fundamental knowledge about materials science and chemistry, it is relatively to deduce the acetone removal mechanism. It should be composed of three successive steps: 1) acetone molecules were adsorbed on the surface of honeycomb nanofibers owing to the Brownian motion; 2) the acetone molecules were diffused into the inner pores of honeycomb fibers thanks to the core adsorption sites provided by the OPM distributed in the PAN fibers; and 3) acetone molecules were adsorbed through the molecular interactions between carboxyl group of acetone and Si-O groups of OPM [16].

This material story can not only help the undergraduate students to review their knowledge about chemistry, physics, and material science, but also provoke their interests about the interdisciplinary learning. A better grasp of the knowledge about the material science and engineering would do great favor to their innovation capability because that innovation is easiest to appear at the edge of interdisciplinary.

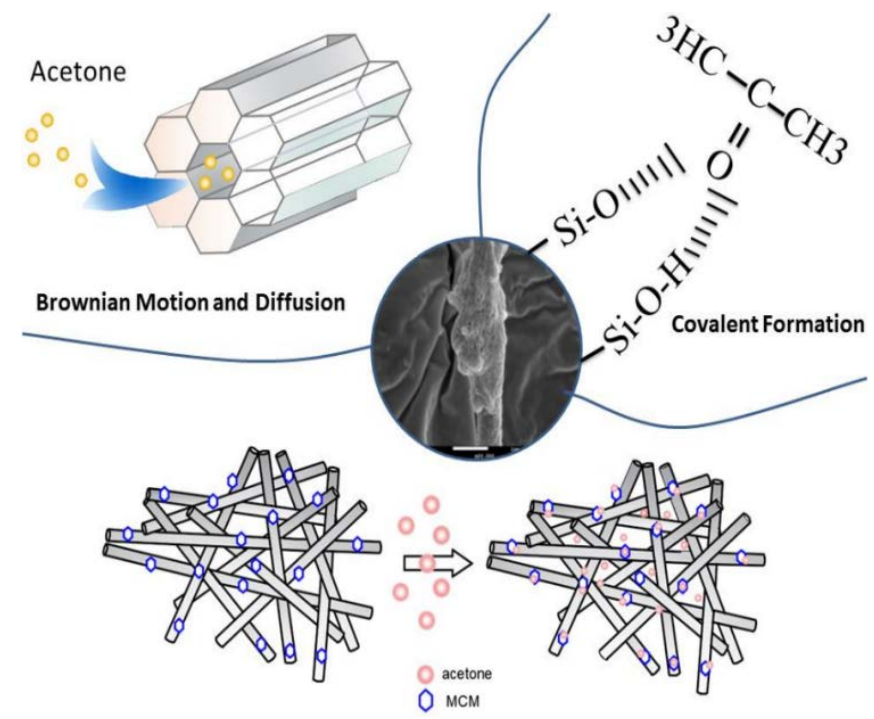

Fig. 3. A diagram showing that the knowledge about material science and engineering can be fine teaching materials for cultivating the undergraduate students about how to treat polluted atmosphere [16].

Electrospinning is a routine electrohydrodynamic atomization process, just as the popular electrospraying [17-23] These methods take advantages of the easy interactions between the working fluids and the high voltage electrostatic energy for creating solid nanofibers or particles [24-27]. The undergraduate students, when they are taught about these advanced materials and material treatment technologies, will greatly expand their images about their specialty with better innovative thinking.

\section{SUMMARY}

Two applied disciplines, Environmental Engineering and Material Science and Engineering, have a big overlapped area. For the college students majoring in them, interdisciplinary teaching should be easy and useful for cultivating professional talents with innovative thinking. With electrospinning and electrospun nanofibers as model advanced technology and advanced functional materials, respectively, the important roles of knowledge about material science and engineering in fostering the undergraduate students are shown. Electrospun 
zein nanofibers are useful materials for removing $\mathrm{Pb}$ from wastewater, and molecular sieve-loaded PAN nanofibers are highly efficacious in absorbing acetone from the surroundings. These two examples about material design, processing and applications are vivid interdisciplinary teaching materials for training students.

\section{ACKNOWLEDGMENT}

The financial supports are from the Shanghai Education Science Research Project (C17058) and the College innovation projects (SH2019217/222/230).

\section{REFERENCES}

[1] H.F. Wen, C. Yang, D.G. Yu, X.Y. Li, D.F. Zhang, "Electrospun zein nanoribbons for treatment of lead-contained wastewater,” Chem. Eng. J., vol.290, pp.263-272, 2016.

[2] Y. Yang, W. Li, D.G. Yu, G. Wang, G.R. Williams, Z. Zhang, “Tunable drug release from nanofibers coated with blank cellulose acetate layers fabricated using tri-axial electrospinning,” Carbohydr. Polym., vol.203, pp.228-237, 2019.

[3] X. Liu, Y. Yang, D.G. Yu, M.J. Zhu, M. Zhao, G.R. Williams, “Tunable zero-order drug delivery systems created by modified triaxial electrospinning,” Chem. Eng. J., vol. 356, pp.886-694, 2019.

[4] Y.Y. Yang, Z.P. Liu, D.G. Yu, K. Wang, P. Liu, X. Chen, "Colonspecific pulsatile drug release provided by electrospun shellac nanocoating on hydrophilic amorphous composites,” Int. J. Nanomed., vol.2018, pp. 2395-2404, 2018.

[5] K. Wang, X.K. Liu, X.H. Chen, D.G. Yu, Y.Y. Yang, and P. Liu, "Electrospun hydrophilic Janus nanocomposites for the rapid onset of therapeutic action of helicid,” ACS Appl. Mater. Interfaces, vol.10, pp.2859-2867, 2018.

[6] H. Zhou, Z. Shi, X. Wan, H. Fang, D.-G. Yu, X. Chen, P. Liu, "The relationships between process parameters and polymeric nanofibers fabricated using a modified coaxial electrospinning,” Nanomaterials, vol.9, no.843, 2019

[7] W. Huang, Y. Hou, X. Lu, Z. Gong, Y. Yang, X.-J. Lu, X.-L. Liu, D.G. $\mathrm{Yu}$, "The process-property-performance relationship of medicated nanoparticles prepared by modified coaxial electrospraying," Pharmaceutics, vol.11, no.226, 2019.

[8] J.J. Li, Y.Y. Yang, D.G. Yu, Q. Du, X.L. Yang, "Fast dissolving drug delivery membrane based on the ultra-thin shell of electrospun coreshell nanofibers,” Eur. J. Pharm. Sci., vol.107, pp.195-204, 2018.

[9] X. Liu, W. Shao, M. Luo, J. Bian, D.G. Yu, "Electrospun blank nanocoating for improved sustained release profiles from medicated gliadin nanofibers,” Nanomaterials, vol.8, no.184, 2018.10

[10] W. Huang, Y. Yang, B. Zhao, G. Liang, S. Liu, X.-L. Liu, and D.G. Yu, "Fast dissolving of ferulic acid via electrospun ternary amorphous composites produced by a coaxial process," Pharmaceutics, vol.10, no. 115,2018

[11] T. Hai, X. Wan, D.G. Yu, K. Wang, Y. Yang, Z.P. Liu, "Electrospun lipid-coated medicated nanocomposites for an improved drug sustainedrelease profile,” Mater. Design, vol.162, pp.70-79, 2019.
[12] H. Wen, L. Gu, H. Yu, X. Qiao, D. Zhang, J. Ye, "Radical assisted iron impregnation on preparing sewage sludge derived $\mathrm{Fe} /$ carbon as highly stable catalyst for heterogeneous Fenton reaction,” Chem. Eng. J., vol.352, pp.837-846, 2018.

[13] Y.H. Wu, D.G. Yu, H.P. Li, X.Y. Wu, and X.Y. Li, "Medicated structural PVP/PEG composites fabricated using coaxial electrospinning,” e-Polymers, vol.17, pp.39-44, 2017.

[14] D.G. Yu, J.J. Li, G.R. Williams, and M. Zhao, "Electrospun amorphous solid dispersions of poorly water-soluble drugs: A review,” J. Control. Release, vol. 292, pp.91-110, 2018.

[15] Y. Xu, J.J. Li, D.G. Yu, G.R. Williams, J.H. Yang, and X. Wang, "Influence of the drug distribution in electrospun gliadin fibers on drugrelease behavior,” Eur. J. Pharm. Sci., vol.106, pp.422-430, 2017.

[16] Y. Wang, H. Tao, D. Yu, C. Chang, "Performance assessment of ordered porous electrospun honeycomb fibers for the removal of atmospheric polar volatile organic compounds," Nanomaterials, vol.8, no.350, 2018.

[17] D.G. Yu, X. L. Zheng, Y. Yang, X. Y. Li, G.R. Williams, M. Zhao, "Immediate release of helicid from nanoparticles produced by modified coaxial electrospraying,” Appl. Surf. Sci., vol.473, pp.148-155, 2019.

[18] X.Y. Li, Z.B. Zheng, D.G. Yu, X.K. Liu, Y.L. Qu, and H.L. Li, "Electrosprayed sperical ethylcellulose nanoparticles for an improved sustained-release profile of anticancer drug," Cellulose, vol.24, pp.55515564, 2017.

[19] Z.P. Liu, Y.Y. Zhang, D.G. Yu, D. Wu, and H.L. Li, "Fabrication of sustained-release zein nanoparticles via modified coaxial electrospraying,” Chem. Eng. J., vol.334, pp.807-816, 2018.

[20] Z.P. Liu, L.L. Zhang, Y.Y. Yang, D. Wu, G. Jiang, and D.G. Yu, "Preparing composite nanoparticles for immediate drug release by modifying electrohydrodynamic interfaces during electrospraying," Powder Technol., vol.327, pp.179-187, 2018.

[21] Y.Y. Yang, M. Zhang, K. Wang, and D.G. Yu, "pH-sensitive polymer nanocoating on hydrophilic composites fabricated using modified coaxial electrospraying,” Mater. Lett., vol.227, pp.93-96, 2018.

[22] Q. Wang, D.G. Yu, L.L. Zhang, X.K. Liu, Y.C. Deng, and M. Zhao, "Electrospun hypromellose-based hydrophilic composites for rapid dissolution of poorly water-soluble drug," Carbohydr. Polym., vol.174, pp.617-625, 2017.

[23] K. Wang, H.F. Wen, D.G. Yu, Y. Yang, and D.F. Zhang, "Electrosprayed hydrophilic nanocomposites coated with shellac for colon-specific delayed drug delivery,” Mater. Design, vol.143, pp.248255, 2018.

[24] Q. Wang, D.G. Yu, S.Y. Zhou, C. Li, and M. Zhao, "Fabrication of amorphous electrospun medicated-nanocomposites using a Teflon-based concentric spinneret," e-Polymer, vol.18, pp.3-11, 2018.

[25] Z. Zhang, W. Li, G. Wang, Y.L. Qu, and D.G. Yu, "Electrospun 4th generation solid dispersions of poorly water-soluble drug utilizing two different processes,” J. Nanomater. vol.2018, no.2012140, 2018.

[26] D.G. Yu, J.J. Li, M. Zhang, and G.R. Williams, "High-quality Janus nanofibers prepared using three-fluid electrospinning," Chem. Commun., vol.53, pp.4542-4545, 2017.

[27] Y.Y. Yang, M. Zhang, Z.P. Liu, K. Wang, and D.G. Yu, "Meletin sustained-release gliadin nanoparticles prepared via solvent surface modification on blending electrospraying,” App. Surf. Sci., vol.434, pp.1040-1047, 2018. 